\title{
How to Get into University
}

THIs is the season when all kinds of young people are either pleased or depressed at the outcome of the annual lottery to decide which 60,000 of them shall be accorded a place at a British university in the year ahead. The process of selection is by now familiar to university authorities, schools and young people whose careers are at stake. What happens is that the Universities Central Council on Admissions, UCCA for short, distributes nearly a year in advance of annual entries to university a series of complicated forms on which young people are asked to make bids for places. In the course of the months which follow, the universities and UCCA collaborate with extraordinary efficiency in singling out some people to whom university places will be awarded without further consultation, others to whom university places will be awarded if performance at the end of the year examinations (A-level) is satisfactory and, presumably, still others who will be denied a place altogether. Inevitably, however, this process cannot fully anticipate the demands on the university system in any one year, with the result that in the hectic few weeks before the university term begins UCCA tries its best to allot people to still vacant places with some semblance of good sense. The process is probably as fair as anybody could expect, but it has a number of built-in pitfalls which conspire to give it an appearance of arbitrariness. But, worse still, the basis on which the allotment of people to places is based is frail on at least three counts. This is the time of the academic year at which they should be remembered.

First, in the actual choice of people to fill particular university places, the UCCA procedure, fair though it may seem, is bound to do rough justice to the wishes and ambitions of a great many young people. After all, when many of them fill in their UCCA forms, it is more than a year to the beginning of the next university year. Nobody in those circumstances can expect to be quite certain that he wishes to follow a particular course of study at some particular university. Indeed, it is in everybody's best interests that young people should at that stage keep their options as open as possible. It is not simply a hankering after tidiness but administrative necessity that makes UCCA forms require too much specific detail of those who fill them in. The result nevertheless is to arrange that a great many square pegs are eventually fitted into a great many round holes. It is, for scientists, particularly poignant that in this process of pre-decision about university places, a good many potential scientists are probably lost to other disciplines.

The process of selection is also offensive because of the way in which it perpetuates the anomalies in the sixth form curriculum. At present, young people at schools are required to make very particular choices about the subjects which they study, and universities, or the better universities, then see it as their task to broaden the education of the new undergraduates. This is an academic folly. Moreover, it has long been recognized as such. Indeed, it is now more than a year since the Schools Council and the Standing Committee on University Education put their heads together and proclaimed that they would work out a more general sixth form curriculum within a few months and certainly in time for this to be discussed by the beginning of the next academic year. There is not much time left for that promise to be implemented. Indeed, the two authorities representing schools and universities respectively seem to have stumbled on the old truth that it only needs a committee of opposing interests to ensure that no reform is possible. It is nevertheless a scandal that nothing has been done, in spite of several protests, to broaden the sixth form curriculum.

Finally, however, the process of university selection is offensive because it exists at all. By now it is clear that the number of people qualified to enter universities is more than twice the number actually able to get there. This is no surprise, even though the optimistic assumptions of the Robbins Report have quickly been shown to be conservative in the short spell since 1963 . So what will happen to the other people-those who do not succeed in the UCCA lottery? The simple answer, of course, is that they will find their way into a course of further study either at a teachers' training college or a technical college. The trouble here, alas, is that these institutions are still regarded as second class institutions, and there is nothing in Government policy to think that they will ever escape from the thrall of trying to be like universities. In short, the Government has got itself in a fearful box in its policy on polytechnics, and it is not by any means too soon to ask whether there should be a reconsideration of the whole policy of binary education with the intention of throwing the balls into the laps of the universities. That in the long run is the only way of making sure that getting into a university will not seem to young people to be a sufficient end in itself. 